\title{
On the Deformation of Dendrites During Directional Solidification of a Nickel-Based Superalloy
}

\author{
J.W. AVESON, G. REINHART, C.J.L. GODDARD, H. NGUYEN-THI, \\ N. MANGELINCK-NOËL, A. TANDJAOUI, J.R. DAVENPORT, N. WARNKEN, \\ F. DI GIOACCHINO, T.A. LAFFORD, N. D'SOUZA, B. BILLIA, and H.J. STONE
}

\begin{abstract}
Synchrotron X-ray imaging has been used to examine in situ the deformation of dendrites that takes place during the solidification of a nickel-based superalloy. By combining absorption and diffraction contrast imaging, deformation events could be classified by their localization and permanence. In particular, a deformation mechanism arising from thermal contraction in a temperature gradient was elucidated through digital image correlation. It was concluded that this mechanism may explain the small misorientations typically observed in single crystal castings.
\end{abstract}

https://doi.org/10.1007/s11661-019-05429-0

(C) The Author(s) 2019

\section{INTRODUCTION}

THE microstructural characteristics of a casting are governed by the thermophysical processes that take place in the mushy zone. ${ }^{[1,2]}$ A detailed understanding of the coupled effects of fluid flow and solute partitioning with the stress, pressure, and temperature fields is therefore required if solidification microstructures are to be controlled. Much of the early work on this topic has emerged from the semi-solid metal (SSM) processing community in an effort to decrease grain size and improve homogeneity by stirring. It has been proposed that crystal multiplication through stirring occurs through dendrite fragmentation via mechanisms involving deformation, recovery, and finally grain boundary wetting. ${ }^{[3,4]}$ Problematically, calculations using

J.W. AVESON, C.J.L. GODDARD, J.R. DAVENPORT, and H.J. STONE are with the Department of Materials Science and Metallurgy, University of Cambridge, 27 Charles Babbage Road, Cambridge CB3 0FS, UK. Contact e-mail: hjs1002@cam.ac.uk G. REINHART, H. NGUYEN-THI, and N. MANGELINCK-NOËL are with the Aix Marseille Université \& CNRS, IM2NP UMR 7334, Campus SaintJérome, Case 142, 13397 Marseille Cedex 20, France. A. TANDJAOUI is with the Aix Marseille Universite \& CNRS, IM2NP UMR 7334 and also with the Laboratoire de Mécanique de Lille (UMR CNRS 8107), Ecole Centrale de Lille, CS-20048, 59651 Villeneuve d'Ascq Cedex, France. N. WARNKEN is with the Department of Metallurgy and Materials, University of Birmingham, Edgbaston B15 2TT, UK. F. DI GIOACCHINO is with the Department of Metallurgical and Materials Engineering, Colorado School of Mines, 1500 Illinois St, Golden, CO. T.A. LAFFORD is with the European Synchrotron Radiation Facility, 71 avenue des Martyrs, CS 40220, 38043 Grenoble Cedex 9, France. N. D'SOUZA is with the Rolls-Royce plc, Derby, DE24 8BJ, UK.

Manuscript submitted November 24, 2018.

Article published online August 26, 2019 tabulated high-temperature material property data have suggested that the fluid flow velocities experienced in all but rapid solidification conditions would be insufficient to damage dendrites mechanically. ${ }^{[5-8]}$ Despite this, there remains a need to incorporate mechanical behavior into the understanding of dendrite deformation and fragmentation, owing to observations of bent dendrites in conventional castings and stirred castings ${ }^{[9-11]}$ and notable efforts are now being made to systematically elucidate the origins of such behavior. ${ }^{[12,13]}$

There are many possible ways in which dendrites may be mechanically loaded during solidification in the mushy zone during investment casting, for example, differential thermal contraction between mold and metal, and buoyancy forces. ${ }^{[14]}$ In single crystal investment castings, used most notably for aerofoil blades for turbine engines, permanent dendrite deformation during solidification is intolerable since grain boundaries reduce creep performance and cannot be removed by subsequent thermomechanical processing. Understanding the mechanistic origins of high- and low-angle boundaries has therefore been an important research topic in the casting community so that strategies to avoid their occurrence may be devised. In the work by Napolitano and co-workers, ${ }^{[15,16]}$ it was identified that, wherever the solidification front has the opportunity to become spread out and disjointed, then a low-angle boundary will form at the surface of convergence where misoriented portions of the front rejoin. They demonstrated how careful design of casting shape and furnace design could be used to ensure that dendrite envelopes did not bifurcate and subsequently reconverge, thus avoiding the potential for grain boundary formation. Investigations of small misorientations in cast components using X-ray topography concluded that the origin of the 
misorientations was thermomechanical deformation in the mushy zone, or just below it. ${ }^{[17]}$ The extent to which such processes occur in casting was quantified at the microstructural level by Husseini et al. who found, using synchrotron X-ray diffraction topography, that most dendrites in castings of René N5 were misoriented. ${ }^{[18]}$ Similar results have been reported in directional castings of Al-Si alloys. ${ }^{[19]}$ These observations are further supported by the research of D'Souza and co-workers, who found evidence of cumulative misorientations along castings of CMSX-4 and identified that this was a result of plastic deformation in the mush. ${ }^{[20-22]}$ Similarly, a study of the origins of sliver defects identified that they arise through mushy zone deformation as a result of differential thermal contraction between metal and mold. ${ }^{[23]}$ As such studies have highlighted the importance of deformation behavior in the semi-solid state, it is clearly highly desirable to have direct evidence of the transient phenomena that give rise to the formation of these macroscopic casting defects.

In the investigation of phenomena that are governed only by thermophysical properties, transparent materials that freeze like metals can readily yield tremendous insight. ${ }^{[24,25]}$ However, in situations where materials do not exhibit analogous behavior, such as mechanical response, it is necessary to use techniques that may directly probe the phenomena using the materials in which they arise. In order to address this, international efforts have been directed towards establishing and using time-resolved, in situ X-ray imaging using synchrotron radiation. These techniques have delivered profound insights into the dynamic processes that occur during solidification. ${ }^{[26]}$ Several studies have been performed using aluminum alloys to investigate the deformation of dendrites that arises as a result of buoyancy forces. These revealed localized deformation of cells or dendrites. ${ }^{[27,28]}$ In addition to the absorption contrast arising from differences in chemical composition, diffraction contrast was used to image the crystal orientation. Diffraction contrast arises when dendrites are oriented such that the Bragg condition is met for one of the allowed reflections of the crystal. Using a polychromatic ("white") beam to ensure that all of the available reflections are captured, the diffracted radiation can then be captured on a wide area film, generating a topograph. ${ }^{[26]}$ Importantly, diffraction also leads to extinctions in the image of the transmitted beam, where the transmitted intensity is decreased as radiation is diffracted out of the field of view. The diffracted and transmitted images can be collected quasi-simultaneously, allowing combined radio-topography. ${ }^{[29]}$ While early studies using these techniques were restricted to low melting temperature materials, the recent development of experimental furnaces capable of high temperatures, while permitting X-ray transmission, has allowed direct investigation of the solidification characteristics of materials with higher melting temperatures, such as steels and silicon. ${ }^{30-32]}$ In addition, the use of image correlation and particle tracking methods have enabled quantitative information to be obtained of the displacement fields associated with the images acquired, for example. ${ }^{[33-36]}$ These experimental advances have permitted new data to be obtained from the transient processes that occur during solidification of metals and alloys and provided new insight into the origins of associated solidification defects.

In this study, synchrotron X-ray radio-topography has been used to characterize the growth and deformation of dendrites in a nickel-based superalloy used in commercial single crystal castings to gain an improved understanding of the origins of defect generation in these materials.

\section{EXPERIMENTAL METHODS}

\section{A. Imaging Data Acquisition}

X-ray imaging was carried out on the BM05 beamline of the European Synchrotron Radiation Facility (ESRF). Rectilinear specimens of dimensions $40 \mathrm{~mm} \times 6 \mathrm{~mm} \times 0.3 \mathrm{~mm}$ of the nickel-based superalloy CMSX-4 were cut and the large area faces ground and polished using $\mathrm{SiC}$ papers and diamond suspension to a $1 \mu \mathrm{m}$ finish. The specimens were then mounted in $\mathrm{X}$-ray transparent boron nitride crucibles consisting of two plates, one of which was recessed in order to contain the specimen. These were bound using Mo clips. This assembly was placed in a bespoke Bridgman furnace designed for high-temperature solidification imaging experiments and described in Reference 37. The specimens were completely melted by raising the temperature of both the top and bottom heaters above the liquidus temperature. The period between melting and solidification of each specimen was minimized as far as practicable in order to limit the extent of reaction between the specimen and the crucible. Resolidification was achieved by controlled cooling of both the top and bottom heaters of the furnace. The bottom heater was typically colder than the upper heater such that a temperature gradient of $\sim 40 \mathrm{~K} \mathrm{~cm}^{-1}$ was established across the sample and solidification could be initiated from near the bottom of the crucible. Throughout the experiment, both the sample and furnace were kept stationary. During solidification, images were recorded using either an ESRF Fast Readout Low Noise (FReLoN) CCD camera ${ }^{[38]}$ with optics giving rise to an image pixel size of $7.46 \mu \mathrm{m}$ at a rate of $0.2 \mathrm{~Hz}$ for the radiography mode, or on photographic film (Agfa Structurix D3-SC, $17.6 \times 12.5 \mathrm{~cm}^{2}$ ) for the topography mode. For the radiographic images, image division against the background of a homogenous liquid ${ }^{[39]}$ was performed using the Image $\mathbf{J}$ software to improve contrast and perform background corrections.

\section{B. Image Processing Using Digital Image Correlation}

Images were analyzed by digital image correlation (DIC) using the DaVis software (version 8.1.0) with the strainmaster module by LaVision $\mathrm{GmbH}$. Conventional 2D-DIC enables mapping of displacement fields $\mathbf{u}(x, y)$ in an $x-y$ plane by comparing pixel intensities of digital images acquired at different stages of deformation. To achieve this, images are divided into subsets of 
rectangular interrogation windows, which are individually cross-correlated to give a measurement of the local displacement. Hence, the displacement mapping can be differentiated to derive the in-plane components of the strain tensor. ${ }^{[40]}$

In the present study, the vector fields were calculated by applying an interrogation window of $25 \times 25$ pixels $^{2}$, which corresponded to an area of $186.5 \times 186.5 \mu \mathrm{m}^{2}$. The interrogation windows overlapped by 20 pet during the calculation, i.e., by 5 pixels, equivalent to $37.3 \mu \mathrm{m}$. The vectors were calculated using the sum of differential method in which the displacement field between the reference and the $n$th image, $\mathbf{u}_{0, n}$ is calculated by

$$
\mathbf{u}_{0, n}=\sum_{i=1}^{n} \mathbf{u}_{i-1, i}
$$

Images were selected where dendritic arrays were well established but showed little evidence of deformation in order to reduce the conflict between growth and deformation. The curl of the displacement field, which describes a counter clockwise rotation about an axis perpendicular to the plane, has been calculated as

$$
\theta=\nabla \times \mathbf{u}=\frac{\partial u_{y}}{\partial x}-\frac{\partial u_{x}}{\partial y}
$$

In the figures shown, the rotation angle (in radians) is shown using an arbitrary color scale.

\section{RESULTS}

\section{A. X-ray Imaging}

Figure 1(a) shows a set of radiographs of dendrites growing in an effective thermal gradient of $3.1 \mathrm{~K} \mathrm{~mm}^{-1}$. The images have been cropped and rotated to show the dendritic microstructure in the region of interest more clearly. To facilitate interpretation of the images, the direction of the gravity vector is shown in the first frame. Four dendrites can be seen and are labeled in the first image. In the initial frame, the dendrites are all aligned parallel with each other. However, in the subsequent images, Dendrite 3 is bent with respect to the other three dendrites. The bending appears to be highly localized and occurs spontaneously at a position approximately one-third of the height of the image. The velocity of the dendrite growth, as determined from the position of their tips, is shown in Figure 1(b) and shows that, collectively, the dendrites initially accelerated before decelerating. Importantly, the growth rate of the bent dendrite (3) can be seen to have decelerated the least while the growth rate of the dendrite against which it converged (4) decelerated the most, consistent with solutal poisoning of the dendrite. ${ }^{[41]}$

Figure 2 shows an X-ray diffraction topograph of a length of one of the growing dendrites, as well as a radiographic image from the same region. X-ray diffraction topography is highly sensitive to elastic strain as deviations in lattice parameter lead to diffraction of different wavelengths in the white beam spectrum. This leads to asterism in the diffraction pattern, which is especially visible in the upper part of the current topograph. Topography is also sensitive to local misorientations of the crystal lattice. Thus, the cleanliness of the topographic image gives an indication that the strain in the growing solid is low. The fact that several portions of dendrite arms appear close together within the topograph suggests that a single dendrite has been deformed by small amounts at localized positions. ${ }^{\text {[28] }}$ The observation that parts of the dendrite imaged in the topograph appear shifted to the right compared to the accompanying radiograph suggests that regions of the dendrite have small crystallographic misorientations with respect to each other. These observations are consistent with the previous observations of the abrupt changes in orientation of the primary stem implicated in sliver defect formation. ${ }^{[23]}$

Figure 3 shows a set of radiographs that exhibit predominantly diffraction contrast (dark in the radiographs). The underlying reasons that can be responsible for this contrast (out-of-plane bending and torsion) are shown schematically in Figure 4 . When dendrites are deformed, if there is a component of bending out of the plane of the image, or a torque, then there is the possibility for the Bragg condition either to be met or to cease to be met and the extinction in the direct radiograph correspondingly appears or disappears. Regrettably, it is not possible to distinguish between out-of-plane bending and torsional modes from the
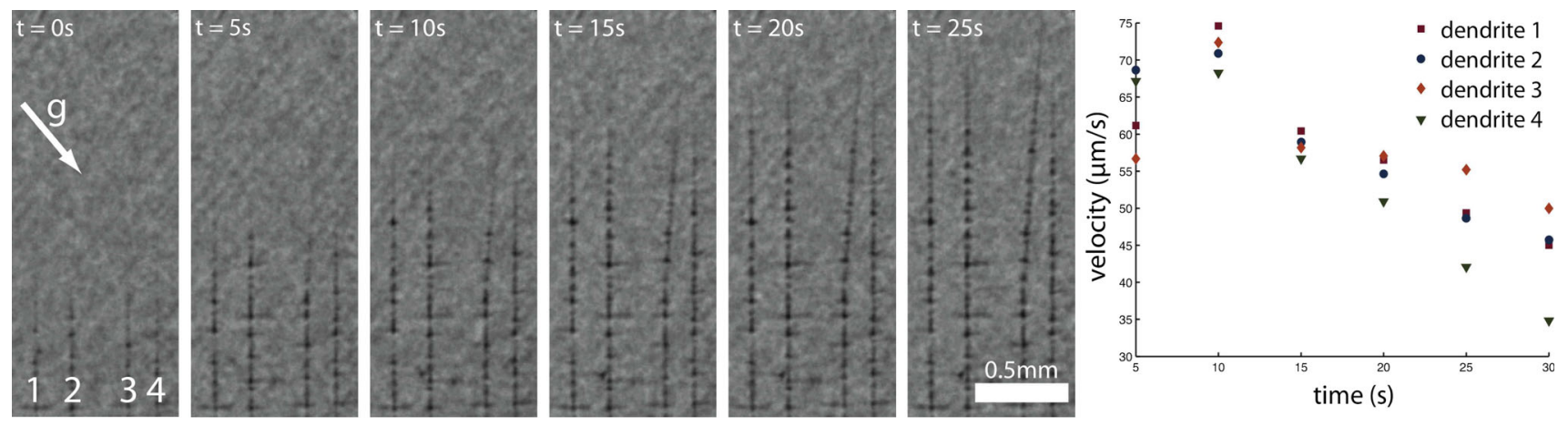

Fig. 1-Time sequence of absorption contrast radiographs showing the effect of deformation on the growth kinetics of an array of dendrites. The graph shows the growth velocity of each dendrite. 


\section{Topography}

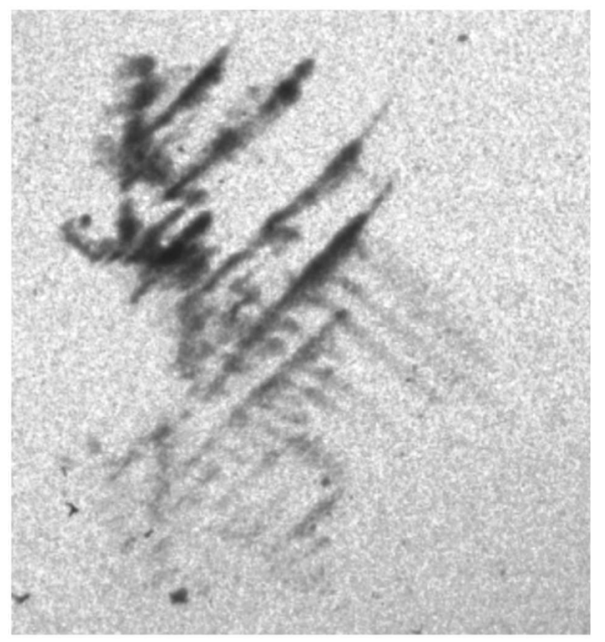

\section{Radiography}

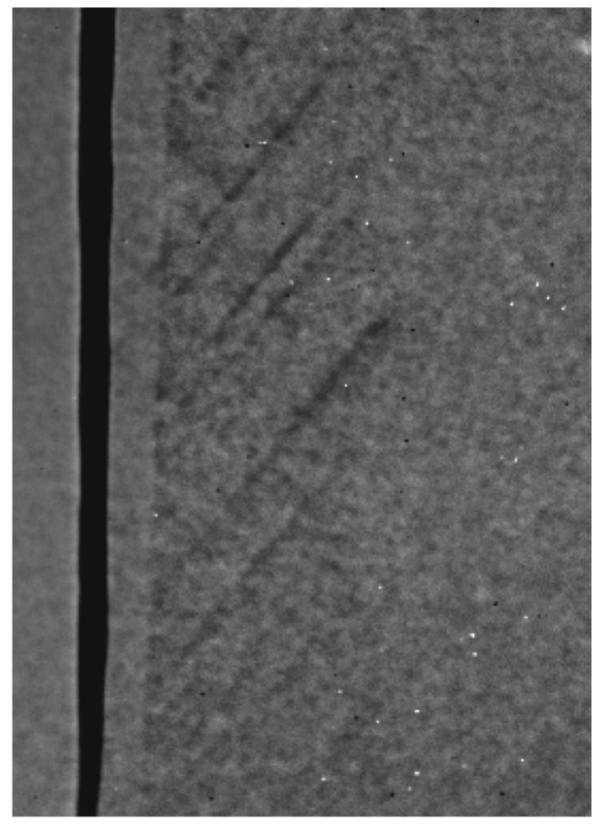

Fig. 2-Diffraction topograph and the associated absorption radiograph of a dendrite in the mushy zone of solidifying CMSX4. These highlight the pristine quality of the as-solidified dendrites and the localized nature of the deformation imparted to them. observed extinction. However, the extent of the dendrite in the extinction condition yields important information about the deformation behavior of the dendrite during solidification. First, only a portion of the dendrite meets the diffraction condition, meaning that the crystallographic orientation of the dendrite is not constant along its length. Second, the position of the extinction is rather sharp, indicating that the change in orientation is highly localized. Third, in the sequence of images shown, the position of the extinction can first be seen to descend and then to re-ascend the primary arm of the dendrite, indicating that the deformation is reversible.

Detailed examination of the dendrites shows that, during solidification, the dendrites move relative to each other as a result of thermal expansion. Figure 5 quantifies this behavior: in Figure 5(a) an example image is shown. The highlighted region was selected as it is near the base of the dendrites and so less prone to any bending. For each acquired image, the intensity was then summed along the length of the dendrite, and then two Gaussian fits were used to identify the position of each of the dendrites (Figure 5(b)). The dendrite positions were then plotted as a function of time and this was fitted with a second-order polynomial (Figure 5(c)). The resulting change in primary dendrite arm spacing is plotted as a function of time (Figure 5(d)).

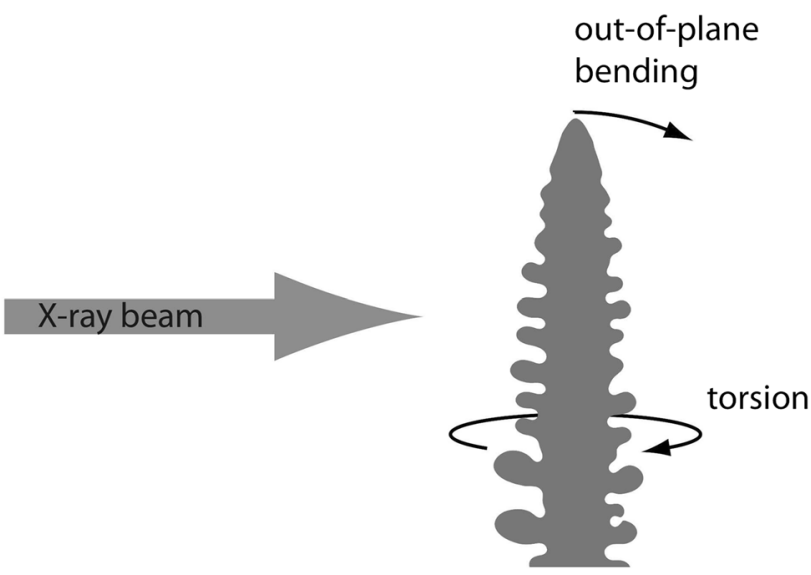

Fig. 4-Schematic diagram illustrating the deformation modes that may give rise to local extinction in the radiograph arising from diffraction, as seen in Fig. 3.
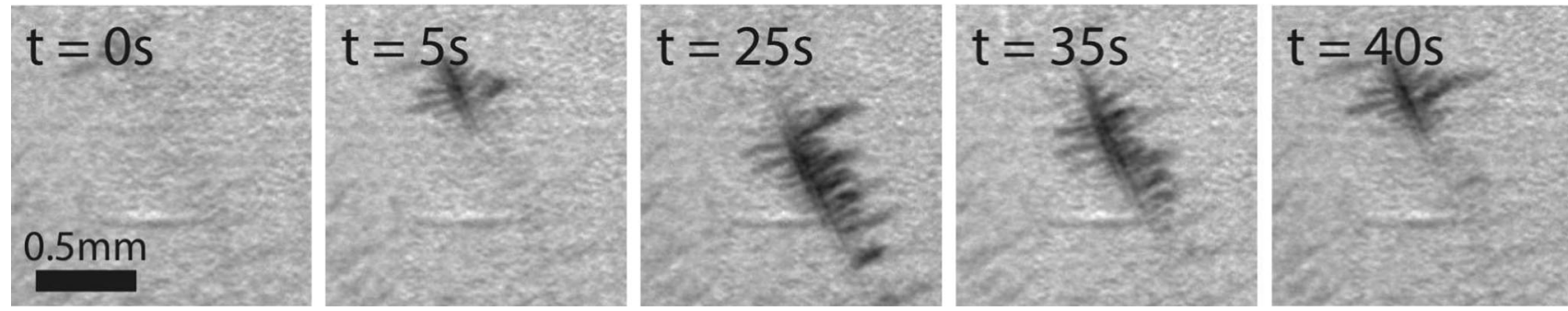

Fig. 3-Radiographs of a dendrite showing extinction where that part of the dendrite satisfies the diffraction condition, at a series of different times during solidification. The region of the dendrite backbone in the diffraction condition varies with time, indicating that it is flexible and its crystallographic orientation is not continuous along the dendrite. 
(a)

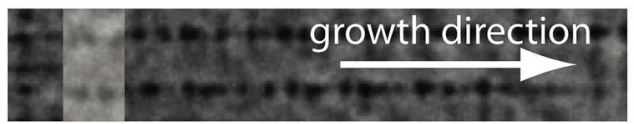

(b)

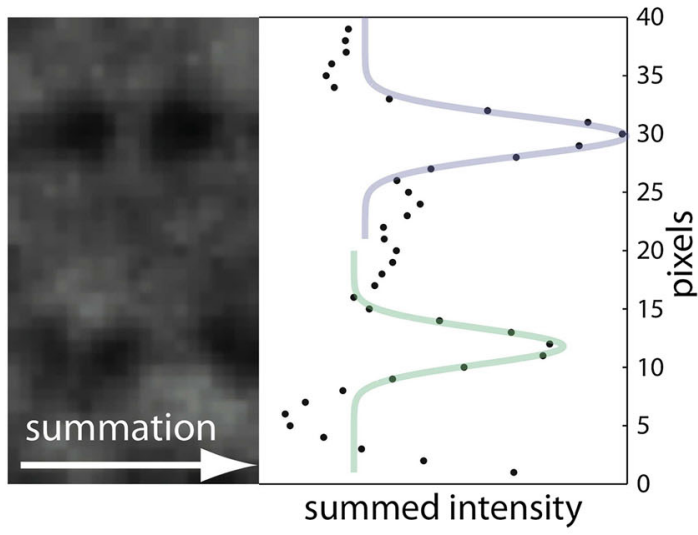

(c)

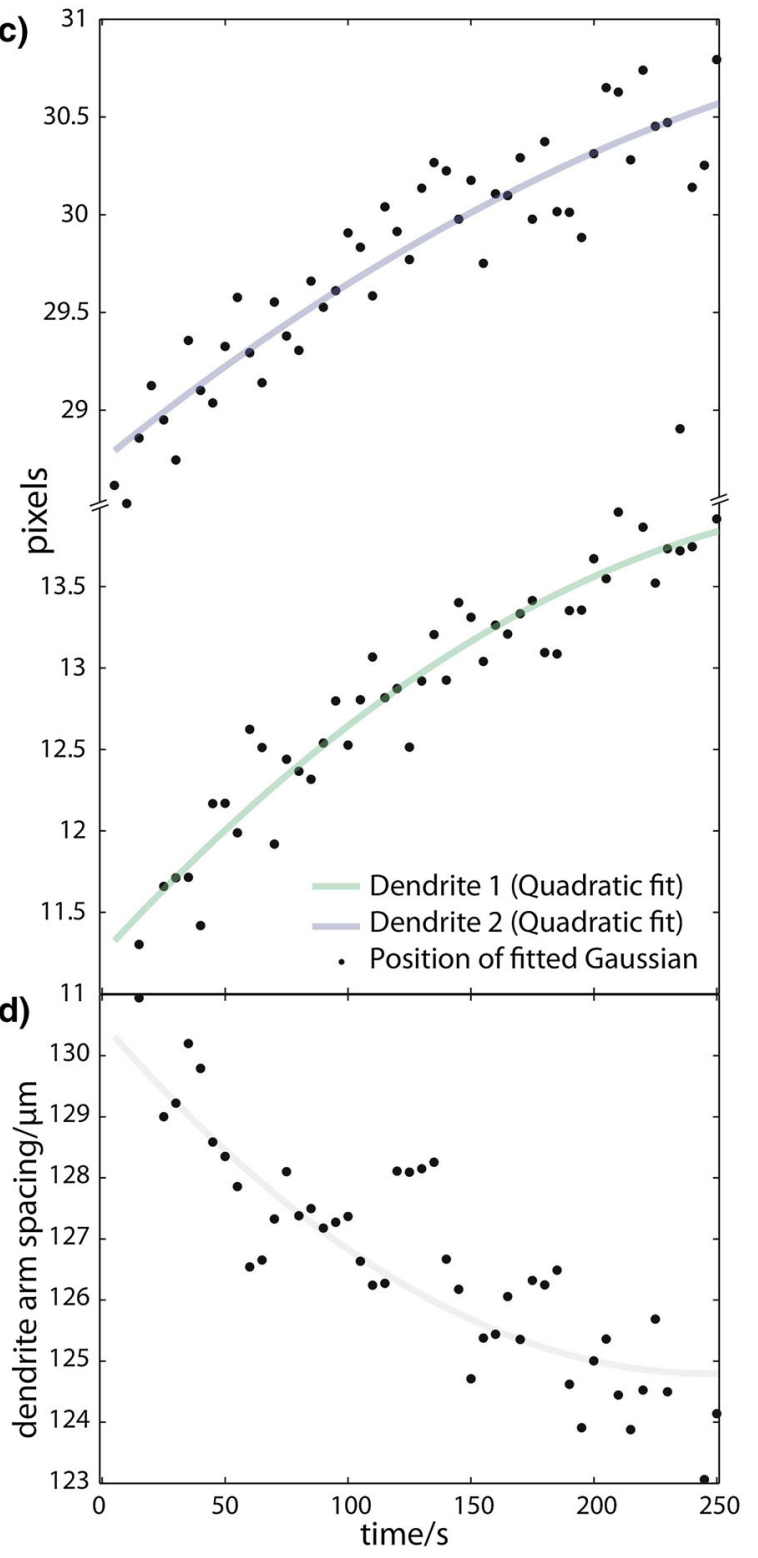

4 Fig. 5-Method of analysis of the motion of dendrites resulting from thermal contraction. The pair of dendrites shown in $(a)$ was summed in the horizontal direction, with the dendrite peaks fitted with Gaussian functions (b). The positions of these Gaussian functions with time are plotted in $(c)$ and interpolating polynomials fitted to the data are indicated by the solid lines. The resultant primary dendrite arm spacing is plotted as a function of time in $(d)$.

In order to assess the effect of the strain on the dendritic microstructure, image correlation was performed using LAVision and the results of this are shown in Figure 6. A pair of dendrites can be seen to have grown in a near-parallel manner from another dendrite arm. At later time steps, the dendrite to the right can be seen to bend to the right. As time elapses, the left dendrite moves in one direction, with the right dendrite in the opposite direction; the magnitude of the rotation increases with time. In the final image, acquired after 320 seconds, the separation of the two dendrites can be seen to increase along the length of the dendrites.

\section{DISCUSSION}

\section{A. Classification of Deformation During Solidification}

The data show that several deformation modes can be activated during solidification. These are discussed in terms of two characteristics: their localization and permanence. Figure 1 shows spontaneous, localized, permanent deformation of a dendrite arm. The direction of the gravity vector suggests that body forces induced this bending. The occurrence of such deformation influences growth kinetics and, in the case observed, would lead to a low- to medium-angle grain boundary forming at the surface of convergence of the secondary arms. This is consistent with the conclusion of Aveson et al. that sliver grains originating at regions of greater thermal stress are the result of deformation in the mushy zone. ${ }^{[23]}$ The diffraction topograph in Figure 2 shows another, different, example of localized deformation of otherwise pristine dendrites. However, as these data are not time-resolved, it is not possible to state whether this deformation is permanent or not. The diffraction contrast radiographic images in Figure 3 are useful in further interpreting this, since the extinction spot is of similar size to the fragments observed by diffraction topography in Figure 2. In Figure 3, the extinction spot moves up and down the dendrite. This demonstrates that, in this case, the dendrite deformation is reversible as previously observed in aluminum alloys ${ }^{[28]}$ and is unlikely to have occurred as a consequence of gravity loading. Since only a portion of the dendrite meets the diffraction condition, it can be concluded that the dendrite backbone is rather flexible in the mushy zone, as also seen in Reference 42. While the bending observed in Figure 6 is less apparent, there are clear 'hot spots' of increased bending. Importantly, it appears that the hot spots are more prevalent above positions where a secondary dendrite impinges upon the adjacent secondary dendrite and do not just arise as a consequence 


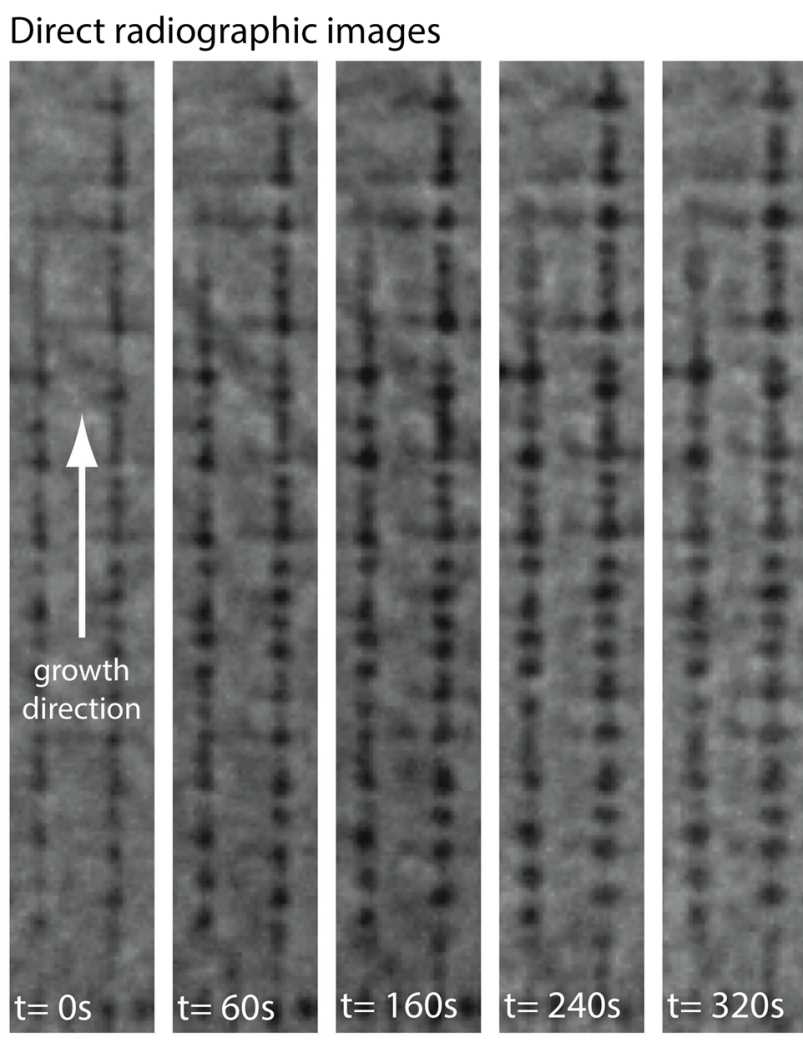

Image correlation overlays

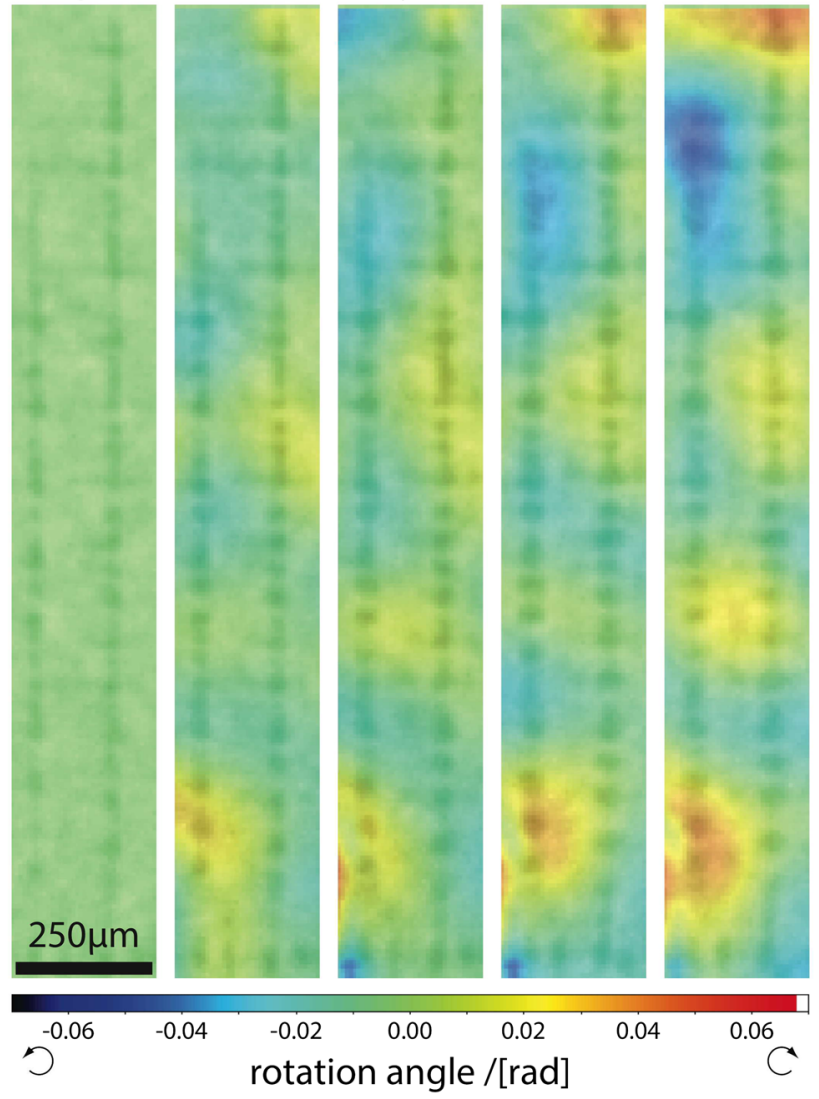

Fig. 6-Radiographic images with associated image correlation maps showing how the dendrites deform during solidification. of gravity loading, which would be expected to affect many dendrites in a similar manner.

\section{B. Bending of Aligned Dendrites Through Contraction in a Thermal Gradient}

It is well known that dendrites are generated as the result of the breakdown of a planar solid-liquid interface by perturbations. ${ }^{[43]}$ In the case of single crystal castings, the dendrites emerge either from the breakdown of a planar seed melt-back interface, or from lower order dendrites, such as tertiary dendrite arms that appear to grow as primary dendrite arms. In either of these cases, if the substrate from which the dendrites emerge undergoes thermal contraction, then the initial spacing of the dendrites will be decreased. ${ }^{[44]}$ This can be seen to occur in Figure 5, where the dendrite arm spacing can be seen to have reduced from 130 to $124 \mu \mathrm{m}$ during the course of the experiment.

When dendrites are free to move, contraction can be accommodated without the dendrites being deformed. However, at high solid fractions, secondary dendrite arms impinge against one another and coalesce. ${ }^{[45]}$ Thus, when the dendrites are subsequently translated laterally by the thermal contraction of their substrate, then at the point of impingement, the dendrite experiences a resistance to the translation and this point in essence acts as a fulcrum. Considering a pair of dendrites deforming in this way, the angle subtended between the dendrites will increase as the bases of the dendrites are moved closer together through thermal contraction. The digital image correlation analysis in Figure 6 supports the interpretation that deformation occurs in this way: the dendrites splay out along the length of the dendrite. While this mechanism requires deeper assessment from theory and simulation, it may account for some of the previous observations of small misorientations in castings that have been reported by many authors. ${ }^{[15-17,46]}$ Specifically, it has been observed that the spread of misorientation increases with thermal gradient ${ }^{[17]}$ : from the present perspective, the length along the axis of a dendrite over which the thermal strain must be accommodated is smaller with greater thermal gradients, and so the angles of misorientations developed will be expected to be larger.

\section{CONCLUSIONS}

Synchrotron X-ray radio-topography has been used to probe how dendrites deform during directional solidification of the nickel-based superalloy, CMSX-4, and how this may lead to low-to-medium misorientation defects in cast components through the convergence fault mechanism. Through combined diffraction and absorption contrast imaging, it was observed that dendrites could deform in several ways. Both permanent and transient deformations were observed, as were both localized and cumulative deformations. While some deformation could be directly attributed to gravity 
loading of the dendrites, other deformations modes appeared to arise as a result of other, transient stresses. Specifically, contraction of the dendritic network was also observed, which had the effect of reducing the primary dendrite arm spacing. Digital image correlation of the radiographic images acquired indicated that lateral contraction of the dendrite array as a result of cooling in the imposed temperature gradient leads to the generation of small misorientations between primary dendrites. The effect of deformation on the kinetics of continued solidification was also observed, which showed that, following dendrite bending, the reoriented dendrite may be able to competitively overgrow adjacent dendrites in the convergent condition.

\section{ACKNOWLEDGEMENTS}

J.W.A. and H.J.S acknowledged funding by the EPSRC/Rolls-Royce Strategic Partnership under grants $\mathrm{EP} / \mathrm{H} 022309 / 1, \quad \mathrm{EP} / \mathrm{H} 500375 / 1$, and $\mathrm{EP} /$ M005607/1. The authors are grateful to the ESRF for the provision of beamtime and to $\mathrm{X}$. Guichard for technical assistance with the experiment. The underlying data may be accessed through the University of Cambridge data repository.

\section{OPEN ACCESS}

This article is distributed under the terms of the Creative Commons Attribution 4.0 International License (http://creativecommons.org/licenses/by/4.0/), which permits unrestricted use, distribution, and reproduction in any medium, provided you give appropriate credit to the original author(s) and the source, provide a link to the Creative Commons license, and indicate if changes were made.

\section{REFERENCES}

1. W. Kurz and D.J. Fisher: Fundamentals of Solidification, 4th ed., CRC Press, Boca Raton, 1998.

2. J.A. Dantzig and M. Rappaz: Solidification, EPFL Press, London, 2009.

3. A. Vogel: Met. Sci., 1978, vol. 12, pp. 576-78.

4. R.D. Doherty, H.-I. Lee, and E.A. Feest: Mater. Sci. Eng. A, 1984, vol. 65 , pp. 181-89.

5. J. Pilling and A. Hellawell: Metall. Mater. Trans. A, 1996, vol. 27A, pp. 229-32.

6. A.M. Mullis: Acta Mater., 1999, vol. 47, pp. 1783-89.

7. K. Dragnevski, A.M. Mullis, D.J. Walker, and R.F. Cochrane: Acta Mater., 2002, vol. 50, pp. 3743-55.

8. A.M. Mullis, D.J. Walker, S.E. Battersby and R.F. Cochrane, Mater. Sci. Eng., A, 2001, vol. 304-306, pp. 245-249.

9. R.D. Doherty: Scr. Mater., 2003, vol. 49, pp. 1219-22.

10. S. Ananiev, P. Nikrityuk, and K. Eckert: Acta Mater., 2009, vol. 57, pp. $657-65$.

11. D.B. Spencer, R. Mehrabian, and M.C. Flemings: Metall. Trans., 1972, vol. 3, pp. 1925-32.
12. M. Yamaguchi and C. Beckermann: Acta Mater., 2013, vol. 61, pp. 4053-65.

13. M. Yamaguchi and C. Beckermann: Acta Mater., 2013, vol. 61, pp. $2268-80$

14. R.J. Schaefer, D.R. Black, M.D. Vaudin, B.R. Mueller, and A.F. Giamei: Proceedings of the 4th Decennial Conference on Solidification Processing, University of Sheffield, Sheffield, 1997, p. 73.

15. R.E. Napolitano and R.J. Schaefer: J. Mater. Sci., 2000, vol. 35, pp. 1641-59.

16. R.E. Napolitano and D.R. Black: J. Mater. Sci., 2004, vol. 39, pp. 7009-17.

17. N. Siredey, M. Boufoussi, S. Denis, and J. Lacaze: J. Cryst. Growth, 1993, vol. 130, pp. 132-46.

18. N.S. Husseini, D.P. Kumah, J.Z. Yiuk, C.J. Torbet, D.A. Arms, E.M. Dufresne, T.M. Pollock, J.W. Jones, and R. Clarke: Acta Mater., 2008, vol. 56, pp. 4715-23.

19. J.R. Van Hoose, R.N. Grugel, S.N. Tewari, L.N. Brush, R.G. Erdmann, and D.R. Poirier: Metall. Mater. Trans. A, 2012, vol. 43A, pp. 4724-31.

20. N. D'Souza, M. Newell, K. Devendra, P.A. Jennings, M.G. Ardakani, and B.A. Shollock: Mater. Sci. Eng. A, 2005, vols. 413-414, pp. 567-70.

21. M. Newell, K. Devendra, P.A. Jennings, and N. D'Souza: Mater. Sci. Eng. A, 2005, vol. 412, pp. 307-15.

22. M. Newell, N. D'Souza, and N.R. Green: Int. J. Cast Met. Res., 2009, vol. 22, pp. 66-69.

23. J.W. Aveson, P.A. Tennant, B.J. Foss, B.A. Shollock, H.J. Stone, and N. D'Souza: Acta Mater., 2013, vol. 61, pp. 5162-71.

24. R. Trivedi and K. Somboonsuk: Mater. Sci. Eng., 1984, vol. 65, pp. $65-74$.

25. W. Losert, B.Q. Shi, and H.Z. Cummins: Proc. Natl. Acad. Sci. USA, 1998, vol. 95, pp. 431-38.

26. R.H. Mathiesen, L. Arnberg, H. Nguyen-Thi, and B. Billia: JOM, 2012, vol. 64, pp. 76-82.

27. B. Billia, N. Bergeon, H. Nguyen-Thi, H. Jamgotchian, J. Gastaldi, and G. Grange: Phys. Rev. Lett., 2004, vol. 93, pp. 126105-1-126105-4.

28. G. Reinhart, A. Buffet, H. Nguyen-Thi, B. Billia, H. Jung, N. Mangelinck-Noël, N. Bergeon, T. Schenk, J. Härtwig, and J. Baruchel: Metall. Mater. Trans. A, 2008, vol. 39A, pp. 865-74.

29. G. Reinhart, PhD thesis, Université Paul Cezanne, Aix-Marseill III, 2006.

30. T. Riberi-Béridot, N. Mangelinck-Noël, A. Tandjaoui, G. Reinhart, B. Billia, T. Lafford, J. Baruchel, and L. Barrallier: $J$. Cryst. Growth, 2015, vol. 418, pp. 38-44.

31. H. Yasuda, T. Nagira, M. Yoshiya, N. Nakatsuka, A. Sugiyama, K. Uesugi, and K. Umetani: ISIJ Int., 2011, vol. 51, pp. 402-408.

32. T. Nagira, C.M. Gourlay, A. Sugiyama, M. Uesugi, Y. Kanzawa, M. Yoshiya, K. Uesugi, K. Umetani, and H. Yasuda: Scr. Mater., 2011, vol. 64, pp. 1129-32.

33. K.M. Kareh, P.D. Lee, and C.M. Gourlay: IOP Conf. Ser. Mater. Sci. Eng., 2012, vol. 33, p. 012037

34. C.M. Gourlay, A.K. Dahle, T. Nagira, N. Nakatsuka, K. Nogita, K. Uesugi, and H. Yasuda: Acta Mater., 2011, vol. 59, pp. 4933-43.

35. J. Fonseca, C. O'Sullivan, T. Nagira, H. Yasuda, and C.M. Gourlay: Acta Mater., 2013, vol. 61, pp. 4169-79.

36. S. Terzi, L. Salvo, M. Suéry, N. Limodin, J. Adrien, E. Maire, Y. Pannier, M. Bornert, D. Bernard, M. Felberbaum, M. Rappaz, and E. Boller: Scr. Mater., 2009, vol. 61, pp. 449-52.

37. A. Tandjaoui, N. Mangelinck-Noël, G. Reinhart, J.-J. Furter, B. Billia, T. Lafford, J. Baruchel, and X. Guichard: Energy Procedia, 2012, vol. 27, pp. 82-87.

38. J.C. Labiche, O. Mathon, S. Pascarelli, M.A. Newton, G.G. Ferre, C. Curfs, G. Vaughan, A. Homs, and D.F. Carreiras: Rev. Sci. Instrum., 2007, vol. 78, p. 091301.

39. A. Bogno, H. Nguyen-Thi, N. Bergeon, N. Mangelinck-Noël, T. Schenk, B. Billia, E. Boller, and J. Baruchel: Nucl. Instrum. Methods Phys. Res. B, 2010, vol. 268, pp. 394-98. 
40. M.A. Sutton, J.-J. Orteu, and H.W. Schreir: Image Correlation for Shape, Motion and Deformation Measurements, Springer, New York, 2009.

41. M.A. Martorano, C. Beckermann, and Ch.-A. Gandin: Metall. Mater. Trans. A, 2003, vol. 34A, pp. 1657-74.

42. G. Reinhart, H. Nguyen-Thi, J. Baruchel, and B. Billia: JOM, 2014, vol. 66, pp. 1408-14.

43. W.W. Mullins and R.F. Sekerka: J. Appl. Phys., 1964, vol. 35 , pp. $444-51$.
44. G. Brewster, H.B. Dong, N.R. Green, and N. D'Souza: Metall. Mater. Trans. B, 2008, vol. 39B, pp. 87-93.

45. M. Rappaz, J.-M. Drezet, and M. Gremaud: Metall. Mater. Trans. A, 1999, vol. 30A, pp. 449-55.

46. M. Rappaz and E. Blank: J. Mater. Sci., 1987, vol. 22, pp. 896-906.

Publisher's Note Springer Nature remains neutral with regard to jurisdictional claims in published maps and institutional affiliations. 